\title{
Study on the pyrolytic behaviour of xylan-based hemicellulose using TG-FTIR and Py-GC-FTIR
}

\author{
D.K. Shen ${ }^{a}$, S. Gu ${ }^{\text {a,* }}$, A.V. Bridgwater ${ }^{\text {b }}$ \\ ${ }^{a}$ Energy Technology Research Group, School of Engineering Science, University of Southampton, Highfield, Southampton SO17 1BJ, United Kingdom \\ ${ }^{\mathrm{b}}$ School of Engineering and Applied Science, Aston University, Aston Triangle, Birmingham B4 7ET, United Kingdom
}

\section{A R T I C L E I N F O}

\section{Article history:}

Received 31 July 2009

Accepted 14 December 2009

Available online 4 January 2010

\section{Keywords:}

Hemicellulose

Pyrolysis

TG-FTIR

GC-FTIR

Bio-oil

Char

\begin{abstract}
A B S T R A C T
Two sets of experiments, categorized as TG-FTIR and Py-GC-FTIR, are employed to investigate the mechanism of the hemicellulose pyrolysis and the formation of main gaseous and bio-oil products. The "sharp mass loss stage" and the corresponding evolution of the volatile products are examined by the TG-FTIR graphs at the heating rate of 3-80 K/min. A pyrolysis unit, composed of fluidized bed reactor, carbon filter, vapour condensing system and gas storage, is employed to investigate the products of the hemicellulose pyrolysis under different temperatures $\left(400-690^{\circ} \mathrm{C}\right.$ ) at the feeding flow rate of $600 \mathrm{l} / \mathrm{h}$. The effects of temperature on the condensable products are examined thoroughly. The possible routes for the formation of the products are systematically proposed from the primary decomposition of the three types of unit (xylan, O-acetylxylan and 4-O-methylglucuronic acid) and the secondary reactions of the fragments. It is found that the formation of $\mathrm{CO}$ is enhanced with elevated temperature, while slight change is observed for the yield of $\mathrm{CO}_{2}$ which is the predominant products in the gaseous mixture.
\end{abstract}

(c) 2009 Elsevier B.V. All rights reserved.

\section{Introduction}

Thermal chemical processes are widely regarded as promising methods for utilization of biomass [1-4]. The behaviour of thermal decomposition of cellulose, occupying the largest proportion in biomass (about 50\%), has been extensively investigated in the literature [5-14]. Hemicellulose, constituting 20-35\% (mass) of woody biomass, is the least stable composition among wood components, which is composed primarily of xylans and mannans $[15,16]$. A common standpoint presents that cellulose microfibrils are coated with the hemicellulose in the primary cell wall of the plant, which prevents the flocculation of the cellulose microfibrils [17]. Hemicellulose is considered to cross-link cellulosic polymers, lignin and pectins, providing the structural support to the secondary cell wall in plant [18]. Therefore, the pyrolysis of hemicellulose is of practical importance for better understanding of the pyrolytic behaviour of biomass and improving the design of thermochemical biomass conversion.

The main isothermal and dynamic (varied temperature) studies on hemicellulose (essentially xylan) pyrolysis are extensively reviewed by Di Blasi [15]. The kinetic scheme for thermal decomposition of hemicellulose, classified as one-step and multi-step reaction mechanisms, is also summarized together

\footnotetext{
* Corresponding author.

E-mail addresses: ds1t07@soton.ac.uk, s.gu@soton.ac.uk (S. Gu).
}

with the obtained kinetic parameters. Most of the existing kinetic models are proposed based on the analysis of the visible stage(s) of the mass loss (rate) curve, without involving the evolution of the typical products (such as the acetic acid, acetone, furfural, $\mathrm{CO}, \mathrm{CO}_{2}$ and $\mathrm{CH}_{4}$ ) during the corresponding temperature region(s) or mass loss stage(s).

The distribution of the main products (gas, bio-oil and char) for the pyrolysis of hemicellulose has been investigated using the fixed-bed pyrolysis reactors [19-21] while very limited experimental studies are available for growing important fluidized bed reactor systems. The yield of typical compounds in bio-oil is discussed by Hosoya [21]. Systematic studies have been undertaken for cellulose and lignin [22,23] to identify the chemical pathways for the formation of key products during pyrolysis, while such information is not equally available for hemicellulose. The formation routes of the main products for pyrolyzing hemicellulose need to be established in order to understand its intrinsic cracking mechanism and control the thermal decomposition process to make high value products.

To further improve the understanding of the mechanism of hemicellulose pyrolysis and the formation of its main products, the hemicellulose (O-acetyl-4-O-methylglucurono-xylan) extracted from a hardwood (beech) is investigated with TGA-FTIR (thermogravimetric analysis coupled to Fourier transform infrared spectrometer) and Py-GC-FTIR (pyrolysis-gas chromatographFourier transform infrared spectrometer). The mass loss of hemicellulose under different heating rates, corresponding to 
the formation of the volatile products, is simultaneously determined by the TGA-FTIR in a real-time mode. A fast pyrolysis system, composed of fluidized bed reactor, carbon filter, vapour condensing and gas storage, is employed to investigate the hemicellulose pyrolysis under different temperatures. The composition of the collected bio-oil is characterized by GC-FTIR while the stored gases are analyzed by GC. The formation of the gaseous products (such as $\mathrm{CO}, \mathrm{CO}_{2}$ and $\mathrm{CH}_{4}$ ) and the typical compounds in bio-oil (such as methanol, acetone, acetic acid, furfural, aldehyde and so on) are intensively discussed, according to the proposed chemical pathways for hemicellulose primary reactions and the secondary decomposition of fragments.

\section{Materials and methods}

\subsection{Materials}

The sample tested in the experimental is the hemicellulose (Oacetyl-4-O-methylglucurono-xylan) extracted from beech, which is the commercial product from Sigma Chemical Co. The sample was prepared as the white powders with average diameter of $200 \mu \mathrm{m}$, and the content of $\mathrm{C}, \mathrm{H}, \mathrm{S}$ and $\mathrm{O}$ is analyzed to be 40.8 , $6.38,0.26$ and $41.01 \%$, respectively.

It is known that hardwood hemicellulose are mainly composed of xylans, linearly constituted of 1,4 linked $\beta$-xylopyranosyl units [18]. The 4-0-methylglucurono-xylan from beech gives a xyloseto-uronic ratio of $8: 1$, i.e. every eighth xylopyranosyl unit is substituted by the 4-0-methylglucuronic acid unit linked to xylan chain through $(1,2)$ linkage [24]. It is also estimated that acetyl group content varies from 8 to $14 \%$ in every 8 -xylose units, normally representing 3-7 acetyl groups which are linked to $C_{2}$ (sometimes $\mathrm{C}_{3}$ ). The above findings imply the speculative chemical structure of the hemicellulose sample (O-acetyl-4-O-methylglucurono-xylan) in Fig. 1, which also exhibits the detailed substituting positions of the acetyl groups and 4-O-methylglucuronic acid (4-O-MeGlcA) unit to the xlyan chain. Compared to cellulose, the degree of polymerization of the xylan units is very low, less than 200 .

\subsection{TGA-FTIR experiment}

Thermogravimetric analyzer (Mettler Toledo TGA/SDTA 8951E) is coupled to the FTIR spectrophotometer (Netxus 670, Nicolet) to investigate the mass loss of hemicellulose and formation of typical products at the same time. In the TGA experiment, the sample of hemicellulose powders is heated from 30 to $900{ }^{\circ} \mathrm{C}$ at heating rate of 3, 10, 20 and $80 \mathrm{~K} / \mathrm{min}$ under the inert atmosphere. The mass of the sample is less than $5 \mathrm{mg}$ to avoid the possible temperature

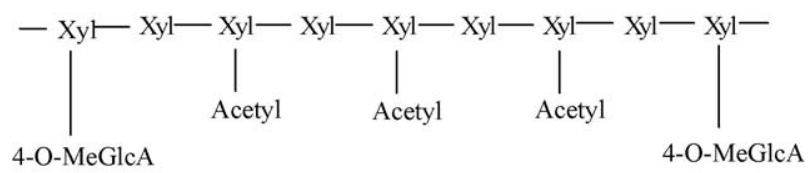

(1) O-acetyl-4-O-methylglucurono-xylan

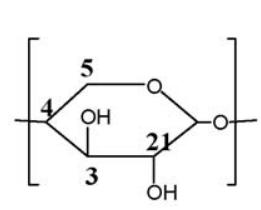

(2) Xylan unit

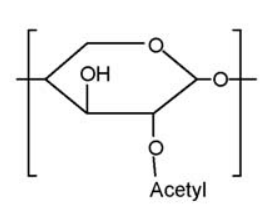

(3) O-acetyl xylan

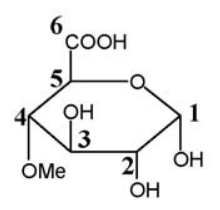

(4) 4-O-MeGIcA
Fig. 1. The chemical structures of the hemicellulose sample and its side-chain unit. gradient in the sample and to ensure the kinetic control of the process [25]. During the experiment the cell of TGA is flushed with $40 \mathrm{ml} / \mathrm{min}$ nitrogen to maintain an inert atmosphere for thermal decomposition of the sample.

The FTIR is connected to TGA by a flow cell which is heated to $180{ }^{\circ} \mathrm{C}$ to prevent condensation of the produced gases on the cell wall. The FTIR spectrometer is set to collect 32 interferograms at a resolution of 4 wavenumbers with a scanning rate of $0.6329 \mathrm{~cm} / \mathrm{s}$ and the spectral range is set to be $4000-400 \mathrm{~cm}^{-1}$. All the interferograms are collected during the pyrolysis and postprocessed to obtain the absorption spectra and the corresponding gas formation profiles. The spectrometer starts $1 \mathrm{~min}$ before the TG experiment. At a nitrogen flow rate of $60 \mathrm{ml} / \mathrm{min}$, about $52.05 \mathrm{~s}$ is required to completely fill the cell volume of the spectrometer. Thus, there is a 2-min lag between the TGA result and the corresponding spectra.

\subsection{The fast pyrolysis unit}

\subsubsection{The apparatus}

The pyrolysis unit, is composed of feeding system, pyrolysis system, carbon filter, vapour condensing and gas storage, as shown in Fig. 2. The reactor is a quartz tube (diameter of $15 \mathrm{~mm}$, length of $1200 \mathrm{~mm}$ and thickness of $2 \mathrm{~mm}$ ) heated by the carborundum heater with the power of $8 \mathrm{~kW}$, while there is a $4 \mathrm{~mm}$ gap to ensure the same temperature in the tube and heater. Temperature is not evenly distributed within the heater and the difference between the distributed points decreases at higher temperature. Hereof, the linearly averaged value is adopted in the experiment.

It should be noted that the mass balance can be easily performed with the testing unit. The feeding system and carbon filter can be disassembled from the quartz tube reactor at the conjunctions 1 and 2 in Fig. 2. The weight of feedstock (about $5 \mathrm{~g}$ ) can be determined precisely without pre-heating reactions before the feeding system is connected to the reactor. The carbon filter is disassembled after the experiment to obtain the weight of char residue by checking the weight difference of the carbon filter.

The bio-oil is collected by the two-step condensing system. The first condenser employs the mixture of water and ice to cool the volatile stream while most of the high molecular weight compounds (heavy bio-oils) and water are condensed and collected in the $U$ tube. The hot stream is cooled down to $50{ }^{\circ} \mathrm{C}$ after the first condenser, and then passes through the second condenser where the light bio-oils are coagulated by the mixture of dry ice and acetone (about $-30^{\circ} \mathrm{C}$ ), and finally is collected in a spiral circle tube.

\subsubsection{The process}

While the experimental temperature reaches the fixed value, the feeding system is connected to the reactor via the closed valve 2 in Fig. 2. The flushing flow initially runs for about $1 \mathrm{~min}$ to purge all oxygen out of the system to ensure the inert atmosphere in the reactor tube. Then, the valve 1 is closed and the valve 2 is opened to carry feedstock up to the heated reactor by the feeding flow. The sample is pyrolyzed rapidly inside the reactor, and the stream mixed of produced volatiles and char residues moves upward passing through carbon filter where the char residue is separated. The purified volatile stream then flows through the two-step condensing system where bio-oils are condensed and collected, the non-condensable volatiles together with the carrier gas (nitrogen) are collected by gas sample bags. Hemicellulose is pyrolyzed in this system to investigate the effect of temperature on the process. The temperature is varied from 400 to $690{ }^{\circ} \mathrm{C}$ while the feeding flow rate is constant as $600 \mathrm{l} / \mathrm{h}$ (corresponding to residence time of about $0.5 \mathrm{~s}$ ). 


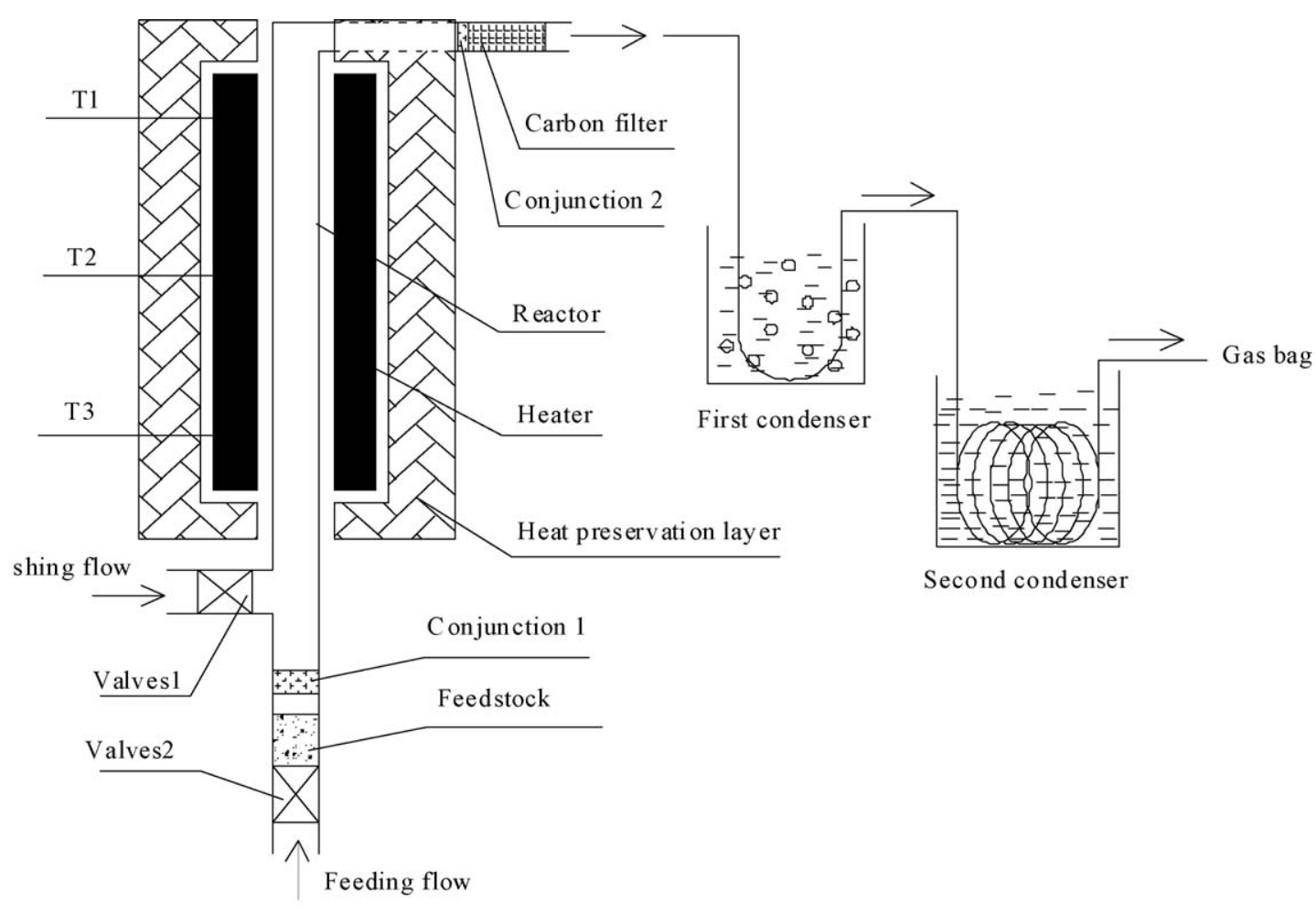

Fig. 2. The apparatus schematics for the biomass pyrolysis and volatiles condensation system.

\subsubsection{The product yield}

The yield of char residue is estimated by the mass difference of the carbon filter before and after the experiment while the yield of the bio-oils is determined by the mass difference of the $U$ tube, spiral circle tube and the connecting tubes. The yield of gaseous products is calculated from the density and volume of the collected gaseous mixture. The density is found from the composition analysis of the mixture by GC(Voyager, Finnigan) while the volume is read from the integral flowmeter. The final yield of the gaseous products is found by excluding the carrier gas $\left(\mathrm{N}_{2}\right)$ in the mixture.

The estimated mass balance closure for the different experiments, described as (the yield of char, bio-oil and gases)/(the mass of feedstock), should be around $100 \%$. Normally there are two runs for each experiment and the one whose deviation exceeds the limitation (5\%) would be repeated.

\subsubsection{The compounds in the bio-oil}

The oxygenated composition in bio-oil is very complicated, and the GC-FTIR technique is employed to analyze compounds in the bio-oil. The column of the GC is applicable for the oxygenated and polar compounds containing hydroxyl, carbonyl and carboxyl groups. The conditions for GC-FTIR is given as: capillary column: Wax-10 (length: $30 \mathrm{~m}$, diameter: $0.25 \mathrm{~mm}$ ), injector temperature: $250{ }^{\circ} \mathrm{C}$; column temperature: $60{ }^{\circ} \mathrm{C}(5 \mathrm{~min}), 60 \rightarrow 250{ }^{\circ} \mathrm{C}$ (heating rate of $10 \mathrm{~K} / \mathrm{min}), 250^{\circ} \mathrm{C}$ ( $\left.25 \mathrm{~min}\right)$; carrier gas: helium, flow rate: $2 \mathrm{ml} / \mathrm{min}$. The set mode for FTIR is the same as described in the section of "TG-FTIR experiments". The yield and the structure of the compounds are determined by the computer software from the characterized GC-FTIR graphs.

\section{Results and discussion}

\subsection{The TG-FTIR analysis}

Fig. 3a and $\mathrm{b}$ shows the TG and DTG curves for hemicellulose under nitrogen at different heating rates. A "sharp mass loss stage" is observed within a narrow range of temperature (from 200 to $350{ }^{\circ} \mathrm{C}$ ), where most of the hemicellulose sample is decomposed by a set of chemical reactions. Most of the mass loss curves (TG curves) are found to decay smoothly from about $400{ }^{\circ} \mathrm{C}$ to the final temperature $900{ }^{\circ} \mathrm{C}$.

$T^{\mathrm{a}}$ and $T^{\mathrm{d}}$ in Table 1 , representing the beginning and the end of the "sharp mass loss stage" respectively, move toward high temperature as the heating rate increases. However, the temperature interval (the difference between $T^{\mathrm{a}}$ and $T^{\mathrm{c}}$ ) seems to be sustained for different heating rates (around $70{ }^{\circ} \mathrm{C}$ ). Two mass loss rate peaks for the "sharp mass loss stage" could be observed in Fig. 3b, shifting toward the high temperature with the increased heating rate, while the temperature gap between the two peaks at different heating rates is similar as about $32{ }^{\circ} \mathrm{C}$ (Table 1 ), consistent with the reported results $[15,26]$. Compared to the case at the lower heating rate, the first peak at the high heating rate is much higher and more visible, while the second peak shows no obvious trend. The first peak is mainly ascribed to the cleavage of the glycosidic bonds and the decomposition of side-chain structure (such as the 4-O-methyglucuronic acid unit), and the second one should be attributed to fragmentation of other depolymerized units (xylan units) [19]. It is difficult to separate the chemical reactions in the two peaks. The decomposition of xylan units would move forward with the elevated heating rate, enhancing the mass loss in the first peak [20]. Thus it is sensible that the first peak is much lower than the second one at the low heating rate $(3 \mathrm{~K} / \mathrm{min})$. At the high heating rate, only one peak would appear, when the decomposition of xylan units is overlapped with that of side-chain structure.

The 3D spectrogram (absorbance-wavenumber-minutes) of the TG-FTIR of hemicellulose under the heating rate of $20 \mathrm{~K} / \mathrm{min}$ is shown in Fig. 4. The composition of volatile products can be determined by the characteristic wavenumber bands, while the yield history of the products can be found by the absorbance against minutes. The temperature corresponding to the absorbance peak is shown as $T_{\max }$ in Table 2 , representing the maximum 

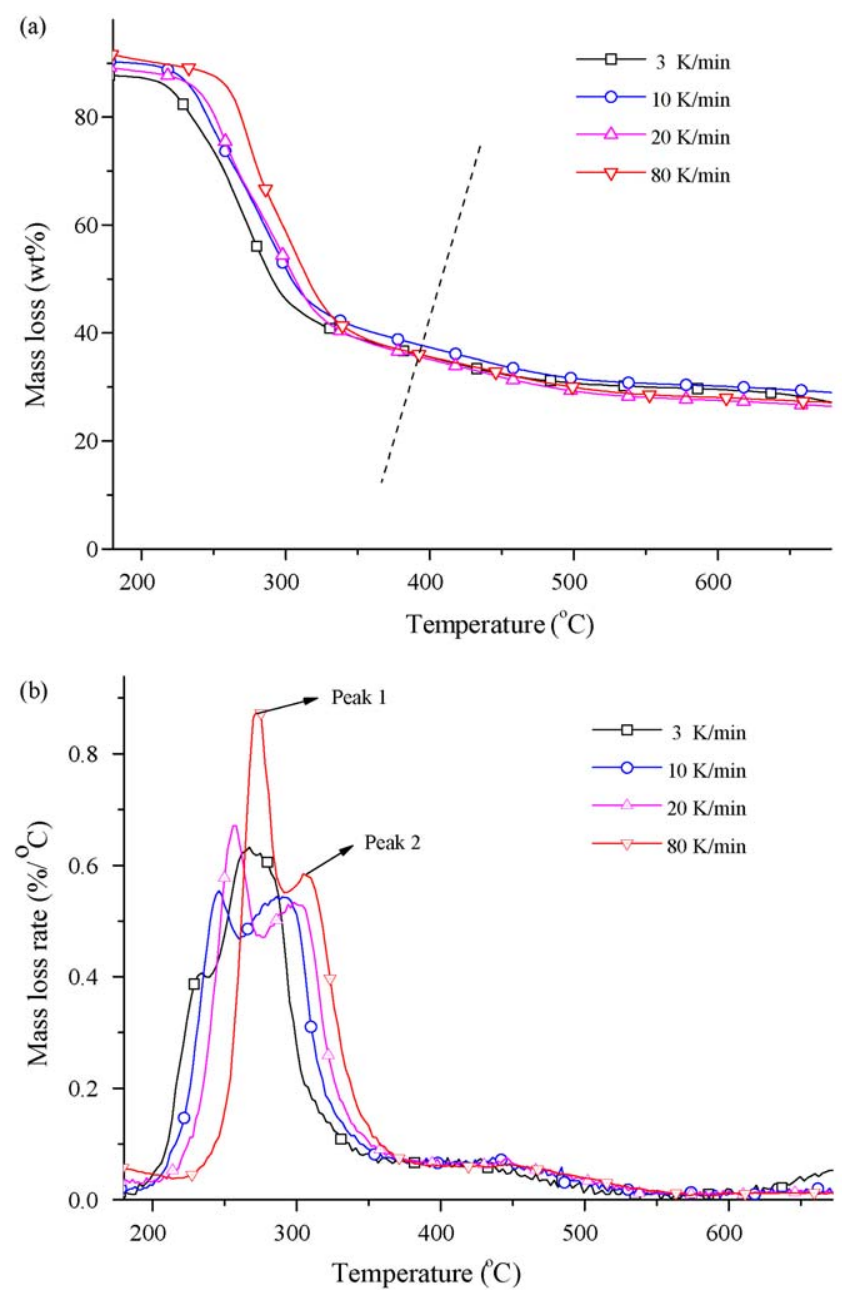

Fig. 3. (a) The TG curves of hemicellulose at the different heating rates. (b) The DTG curves of hemicellulose under the different heating rates.

evolution of the products. It is noted that the values of $T_{\max }$ for the different volatile products (except for $\mathrm{CH}_{4}$ ) in Table 2 are close to $\mathrm{T}^{\mathrm{b}}$ in Table 1 under the same heat rate $(20 \mathrm{~K} / \mathrm{min})$. This implies that various volatiles might reach the maximum production simultaneously and the hemicellulose decomposes intensively within the narrow temperature range. The two sets of visible absorbance peaks (bands 2313-2361 and $669 \mathrm{~cm}^{-1}$ in Fig. 4) show much higher production of $\mathrm{CO}_{2}$ over other gaseous products. It is due to the height of absorbance qualitatively reflects the concentration of the product in the volatile mixture [27].

The detailed evolution of the typical products from the hemicellulose pyrolysis can be explained using the 2D FTIR

Table 1

The characteristic points of the TG and DTG curves of hemicellulose at different heating rates.

\begin{tabular}{ccclclc}
\hline $\begin{array}{l}\text { Heating rate } \\
(\mathrm{K} / \mathrm{min})\end{array}$ & $T^{\mathrm{a}}\left({ }^{\circ} \mathrm{C}\right)$ & $T^{\mathrm{b}}\left({ }^{\circ} \mathrm{C}\right)$ & $\begin{array}{l}(-\mathrm{d} Y / \mathrm{d} T)^{\mathrm{b}} \\
\left(\% /{ }^{\circ} \mathrm{C}\right)\end{array}$ & $\mathrm{T}^{\mathrm{c}}\left({ }^{\circ} \mathrm{C}\right)$ & $\begin{array}{l}(-\mathrm{d} Y / \mathrm{d} T)^{\mathrm{c}} \\
\left(\% /{ }^{\circ} \mathrm{C}\right)\end{array}$ & $\begin{array}{l}T^{\mathrm{d}} \\
\left({ }^{\circ} \mathrm{C}\right)\end{array}$ \\
\hline 3 & 185 & 234 & 0.4070 & 267 & 0.6324 & 354 \\
10 & 190 & 246 & 0.5541 & 290 & 0.5431 & 360 \\
20 & 192 & 256 & 0.6709 & 298 & 0.5337 & 366 \\
80 & 214 & 273 & 0.8782 & 304 & 0.5845 & 369 \\
\hline
\end{tabular}

\footnotetext{
a The minimum mass loss rate $(-\mathrm{d} Y / \mathrm{d} T)$ before the maximum value.

b The first peak of DTG curve.

c The second peak of DTG curve.

d The point when the mass loss rate is less than $0.08 \% /{ }^{\circ} \mathrm{C}$ after the peaks of DTG curve.
}

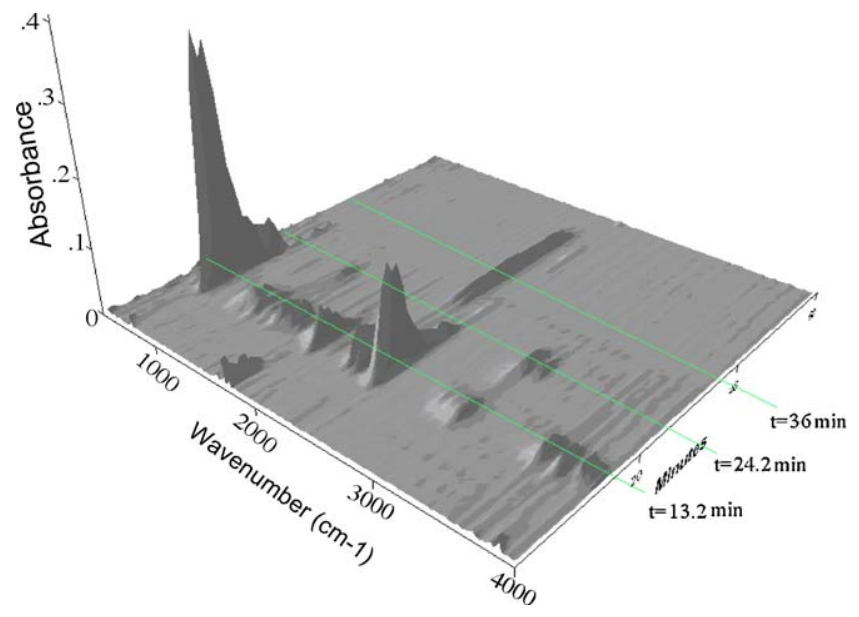

Fig. 4. The 3D spectrogram of TG-FTIR of xylan at the heating rate of $20 \mathrm{~K} / \mathrm{min}$.

spectrogram in Fig. 5 together with the corresponding DTG curve. It is observed that only one visible peak on the evolution curve of $\mathrm{CO}$ and methanol emerges during the "sharp mass loss stage", while two visible peaks are found for the production of $\mathrm{CO}_{2}$, furfural and acetic acid. This indicates that the $\mathrm{CO}$ and methanol are mainly volatilized around the first peak of the sharp mass loss stage, while the second peak is essentially ascribed to the evolution of $\mathrm{CO}_{2}$, aldehyde-type and acetic products. The formation of methanol should be assigned to the $\mathrm{O}$-methyl group lined to the $\mathrm{C}_{4}$ position of the glucuronic acid unit, while the evolution of $\mathrm{CO}$ is attributed to the decarbonylation reactions [20]. The $\mathrm{CO}_{2}$ and acetic acid are evolved through the whole "sharp mass loss stage", mainly due to the cleavage of the acetyl groups from the xylan chain. The furfural is attributed to the ring-open and rearrangement reactions of the xylan unit [19]. This confirms that the ending groups and the side-chain structure are more active, contributing to the first peak in the "sharp mass loss stage", followed by the intensive decomposition of xylan unit for the second peak. Compared to other products, the evolution of $\mathrm{CH}_{4}$ is delayed and reaches its maximum production at the higher temperature, due to the fact that more energy is required to break the $\mathrm{R}-\mathrm{CH}_{3}$ bond and form $\mathrm{CH}_{4}[28]$.

Table 2

The main products of hemicellulose characterized by FTIR at the heating rate of $20 \mathrm{~K} / \mathrm{min}$ and the temperature corresponding to their maximum evolution.

\begin{tabular}{|c|c|c|c|c|}
\hline $\begin{array}{l}\text { Wavenumber } \\
\left(\mathrm{cm}^{-1}\right)\end{array}$ & $\begin{array}{l}\text { Assignment } \\
\text { (Bond) }\end{array}$ & Vibration & Compounds & $T_{\max }\left({ }^{\circ} \mathrm{C}\right)$ \\
\hline $\begin{array}{l}3059-3131 \\
2920-3088\end{array}$ & $\begin{array}{l}\mathrm{C}-\mathrm{H} \\
\mathrm{C}-\mathrm{H}\end{array}$ & $\begin{array}{l}\text { Stretching } \\
\text { Stretching }\end{array}$ & Mainly $\mathrm{CH}_{4}$ & 474 \\
\hline $\begin{array}{l}2150-2212 \\
2058-2131\end{array}$ & $\begin{array}{l}\mathrm{C}-\mathrm{O} \\
\mathrm{C}-\mathrm{O}\end{array}$ & $\begin{array}{l}\text { Stretching } \\
\text { Stretching }\end{array}$ & $\mathrm{CO}$ & 254 \\
\hline $\begin{array}{l}2313-2361 \\
669\end{array}$ & $\begin{array}{l}\mathrm{C}=\mathrm{O} \\
\mathrm{C}=\mathrm{O}\end{array}$ & $\begin{array}{l}\text { Stretching } \\
\text { Dactyl-zone }\end{array}$ & $\mathrm{CO}_{2}$ & 254 \\
\hline $\begin{array}{l}1684-1745 \\
2822-2915\end{array}$ & $\begin{array}{l}\mathrm{C}=\mathrm{O} \\
\mathrm{C}-\mathrm{H}\end{array}$ & $\begin{array}{l}\text { Stretching } \\
\text { Bending }\end{array}$ & $\mathrm{R}-\mathrm{CHO}$ & 254 \\
\hline $\begin{array}{l}1145-1211 \\
1700-1740\end{array}$ & $\begin{array}{l}\mathrm{C}-\mathrm{C} \\
\mathrm{C}=\mathrm{O}\end{array}$ & $\begin{array}{l}\text { Skeleton } \\
\text { Stretching }\end{array}$ & $\mathrm{R}-\mathrm{CO}-\mathrm{R}^{\prime}$ & 254 \\
\hline $\begin{array}{l}1077-1131 \\
3585-3650\end{array}$ & $\begin{array}{l}\mathrm{C}-\mathrm{O} \\
\mathrm{O}-\mathrm{H}\end{array}$ & $\begin{array}{l}\text { Stretching } \\
\text { Stretching }\end{array}$ & $\mathrm{R}-\mathrm{OH}$ & 254 \\
\hline $\begin{array}{l}1210-1260 \\
1690-1800 \\
3503-3569\end{array}$ & $\begin{array}{l}\mathrm{C}-\mathrm{O} \\
\mathrm{C}=\mathrm{O} \\
\mathrm{O}-\mathrm{H}\end{array}$ & $\begin{array}{l}\text { Stretching } \\
\text { Stretching } \\
\text { Stretching }\end{array}$ & $\mathrm{R}-\mathrm{COOH}$ & 254 \\
\hline
\end{tabular}




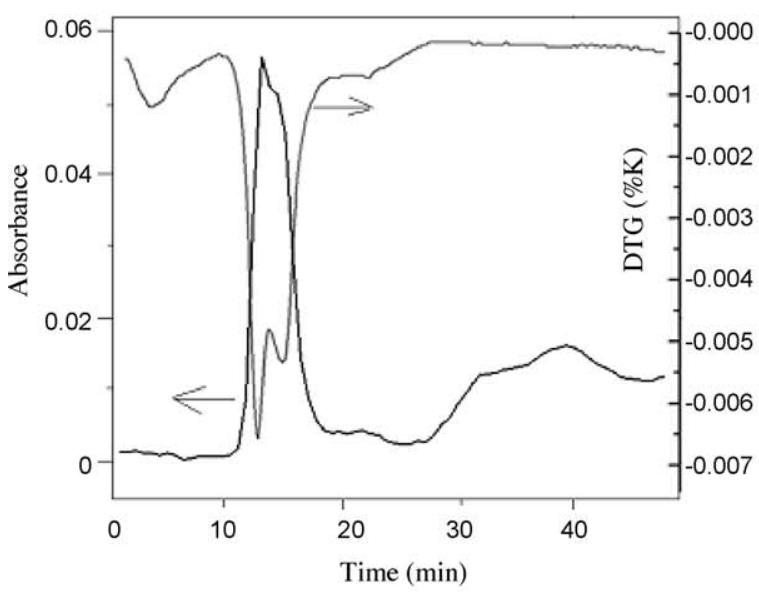

(a): $\mathrm{CO}$

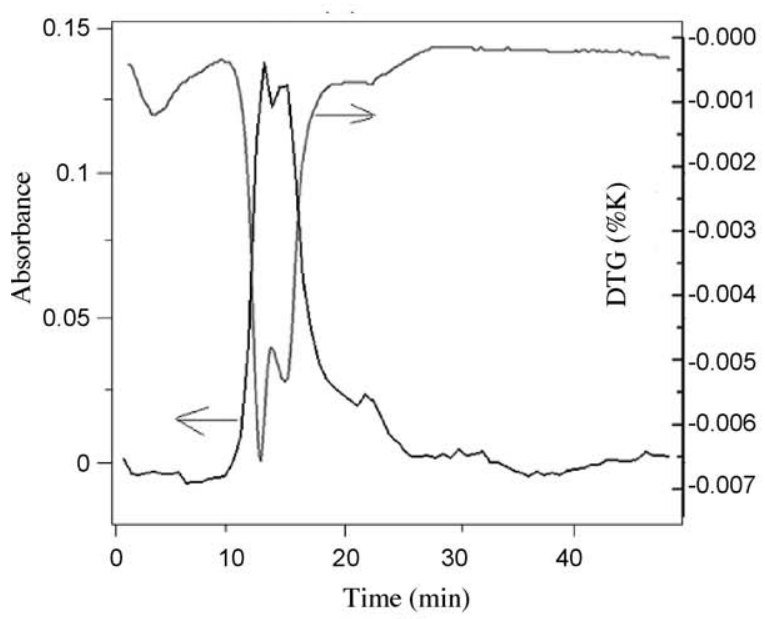

(b): $\mathrm{CO}_{2}$

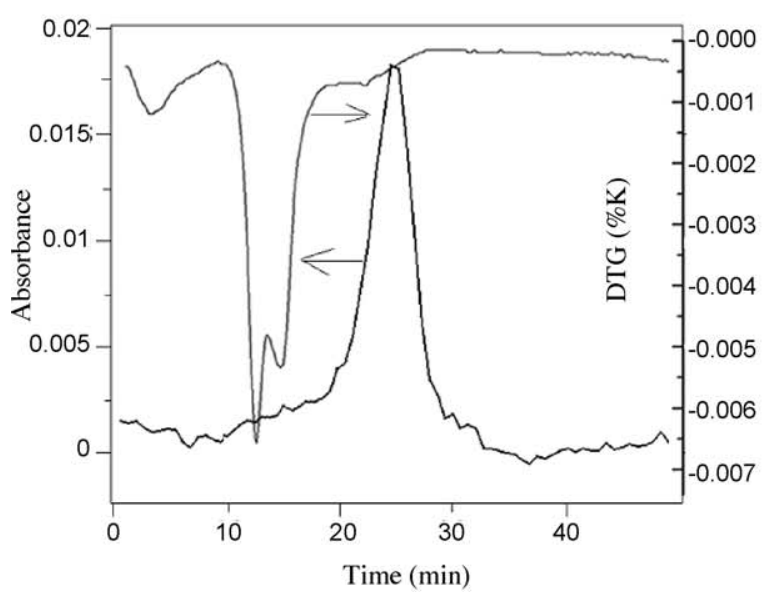

(c): $\mathrm{CO}_{4}$

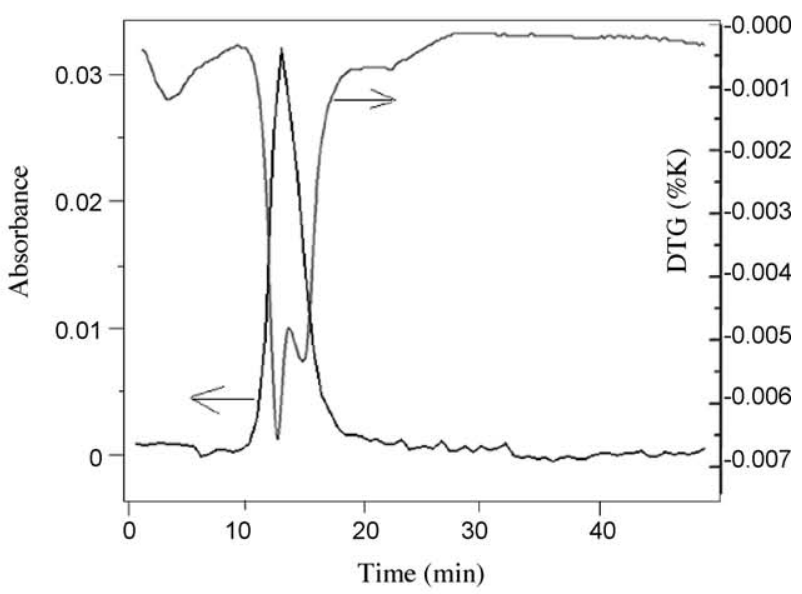

(d): Methanol

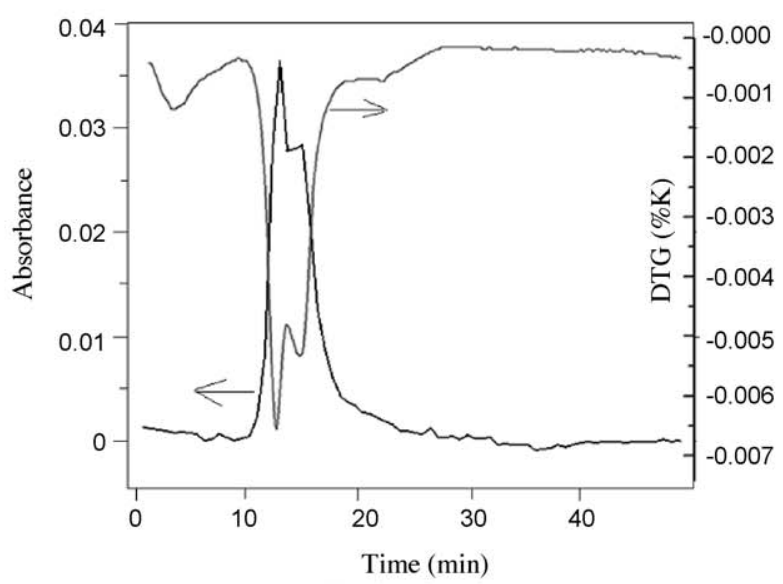

(e): Acetic acid

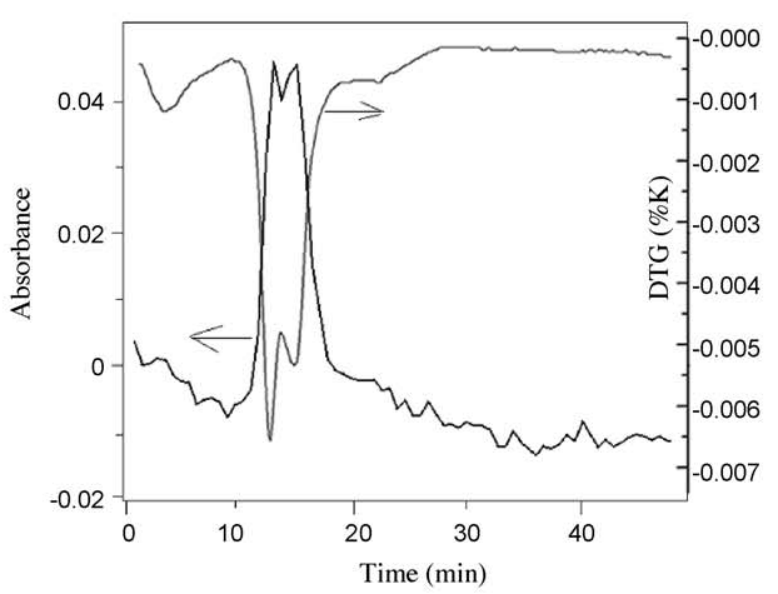

(f): Furfural

Fig. 5. The evolution of the main volatile products from hemicellulose pyrolysis under $20 \mathrm{~K} / \mathrm{min}$ characterized by FTIR corresponding to its DTG curve.

\subsection{Fast pyrolysis experiment}

Hemicellulose samples are tested in the fast pyrolysis testing unit in order to investigate the effects of temperature on the product yield (gas, bio-oil and char). The detailed chemical pathways for the formation of the gaseous and condensible products are proposed and extensively discussed in this section.

\subsubsection{Product (gas, bio-oil and char) distributions}

Fig. 6 shows the yields of the main products (gas, bio-oil and char) under different temperatures (from 400 to $690{ }^{\circ} \mathrm{C}$ ) with feeding flow rate of $600 \mathrm{l} / \mathrm{h}$. It is found that the elevated temperature improves the yield of gas (especially over $475^{\circ} \mathrm{C}$ ) and increases the yield of bio-oil till about $475^{\circ} \mathrm{C}$ followed by gradual decline. It needs to be noted that the yield of char is 


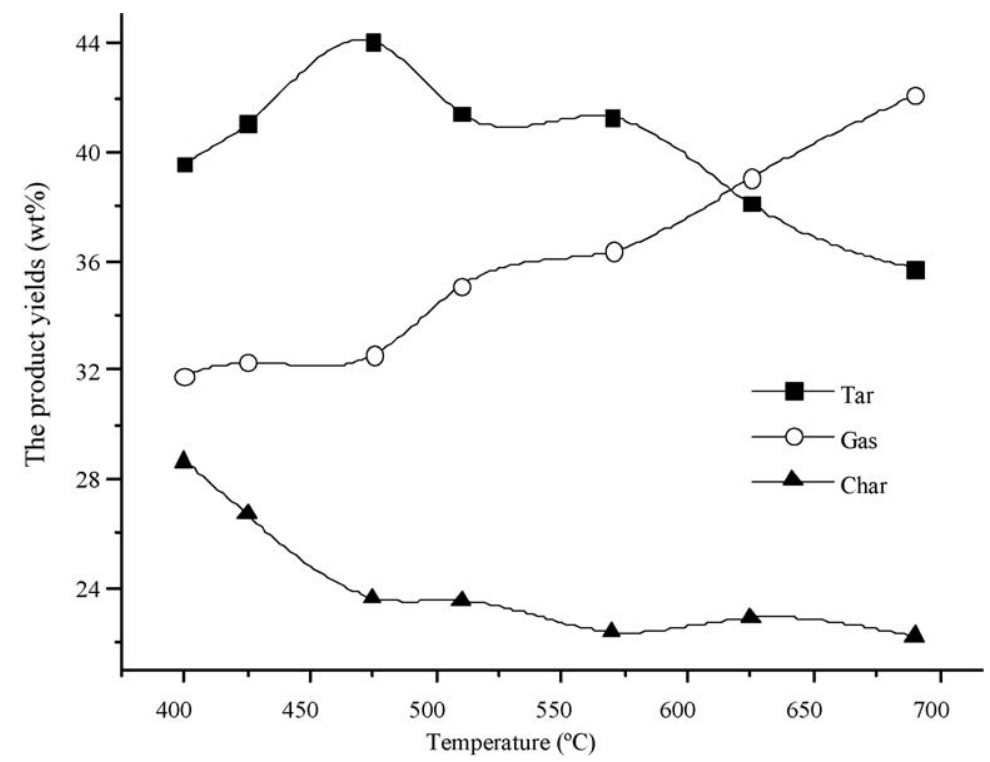

Fig. 6. The yields of bio-oil, gas and char from hemicellulose pyrolysis under different temperatures (feeding flow: $600 \mathrm{l} / \mathrm{h}$ ).

decreased before $475{ }^{\circ} \mathrm{C}$ and remains stable at temperature over $540{ }^{\circ} \mathrm{C}$ (about 22\%).

The production of bio-oil is remarkably increased at the expense of the char before $475^{\circ} \mathrm{C}$, while the yield of the gaseous products is not visibly changed, owing to the fact that more energy is required to propel the secondary reactions (decomposition of the fragments from the primary reactions) to enhance the evolution of the gases. In contrast, the yield of gas at higher temperature is found to increase in proportion to the reduction of bio-oil. These findings indicate that the hybrid mechanism (the combination of competitive and consecutive mechanism) exists for the formation of gas and bio-oil.

\subsubsection{The formation of main condensable products}

The composition of bio-oil from the thermal decomposition of biomass is very complicated and difficult to be fully characterized by a single analytical technique [29]. A number of polar organic compounds in the bio-oil are detected by GC-FTIR analysis in this work. The yields of some typical products in the bio-oil (mass fraction), influenced by the temperature are shown in Table 3. The novelty of the paper is to reveal the detailed mechanism on the reaction mechanism of hemicellulose pyrolysis. Significant contribution comes from the proposed chemical pathways for the cracking of the hemicellulose monomeric units (including the xlyan unit, O-acetyl xylan unit and 4-O-methylglucuronic acid unit) and secondary decomposition of the fragments in Fig. 7a and b.

Table 3 shows that the 1,4-anhydro-D-xylopyranose is one of the main condensable products from the hemicellulose pyrolysis, and the production is decreased at elevated temperature. This indicates that the high temperature inhibit the evolution of this

Table 3

The yield of the main compounds in the bio-oil from the gasification of hemicellulose under different temperatures (feeding flow rate: $600 \mathrm{l} / \mathrm{h}$ ).

\begin{tabular}{llllll}
\hline Compounds & $425^{\circ} \mathrm{C}$ & $475^{\circ} \mathrm{C}$ & $510^{\circ} \mathrm{C}$ & $570^{\circ} \mathrm{C}$ & $690{ }^{\circ} \mathrm{C}$ \\
\hline Methanol (wt\%) & 0.81 & 1.01 & 1.11 & 1.13 & 1.14 \\
Acetic acid (wt\%) & 4.44 & 4.40 & 3.82 & 3.20 & 2.45 \\
Acetone (wt\%) & 0.69 & 0.77 & 0.84 & 1.00 & 1.06 \\
Furfural (wt\%) & 1.94 & 2.30 & 2.40 & 2.86 & 3.16 \\
1,4-Anhydro-D-xylopyranose & 3.84 & 3.43 & 2.85 & 2.01 & 0.69 \\
$\quad$ (wt\%) & & & & & \\
\hline
\end{tabular}

product. The pathway (1) in Fig. 7a presents that the formation of 1,4-anhydro-D-xylopyranose is mainly attributed to the cleavage of the glycosidic linkage of the xylan chain, followed by the rearrangement of the depolymerized molecules. It is reported that the 1,4 intramolecular glycosidic bond on the xylopyranose is less stable than the 1,6 glycosidic bond on the glucopyranose (levoglucose) [20]. This implies that most of the produced 1,4anhydro-D-Xylopyranose would be instantly consumed to produce the two-carbon, three-carbon fragments and gases through the pathways (2), (3), (4), (5) and (6) in Fig. 7a, acting as an intermediate product from the hemicellulose pyrolysis.

The furfural (FF) is regarded as a typical ring-containing product in the bio-oil $[19,20]$. It is found that the yield of furfural is increased as temperature rises, i.e. the high temperature favours the formation of furfural (Table 3). Study [19] shows that the addition of zinc chloride also facilitates the formation of furfural from the hemicellulose pyrolysis. It is achieved through the concerted cleavage of the bond between oxygen and C-5 position and ring-forming between $\mathrm{C}-2$ and $\mathrm{C}-5$ position on the xylan unit along with a free radical of $\mathrm{H}$. Two new chemical pathways are proposed for the production of furfural here. One is ring-opening reaction of the depolymerised xylan unit through the cleavage of the hemi-acetal bond (between oxygen and C- 1 on the pyran-ring), followed by the dehydration between the hydroxyl groups on $C_{2}$ and $C_{5}$ position (pathway $(\mathbf{4}) \rightarrow(8)$ in Fig. 7a). The other is the cleavage of the 1, 2 glycosidic bond between the xylan unit and 4O-methylglucuronic acid unit, followed by the ring-opening reaction and rearrangement of the 4-O-methylglucuronic acid after the elimination of $\mathrm{CO}_{2}$ and methanol (pathway $(\mathbf{1 4}) \rightarrow(\mathbf{1 5}) \rightarrow(\mathbf{8})$ in Fig. 7b). Accordingly it is found that the Oacetylxylan unit has no contribution to the formation of furfural (in Fig. 7b).

Acidic products, especially acetic acid and formic acid, are commonly detected in the bio-oil from the pyrolysis of hemicellulose. The yield of acetic acid is found to decline at elevated temperature, shown in Table 3. It is translated that the formation reactions for acetic acid is less competitive under the high temperature. The prevalent mechanism of the formation of acetic acid is involved with the primary elimination reaction of the active O-acetyl groups linked to the main xylan chain on $C_{2}$ position $[19,20]$, described as the pathway (11) in Fig. 7b. Another chemical pathway for the acetic acid production is attributed to the ketene 
(a)<smiles>C[C@@H]1COC(CCC23COC(OC2)C(O)C3O)C(O)C1O</smiles>
(1) $\uparrow$<smiles>CC1C(O)C(O)OCC1(C)C</smiles>

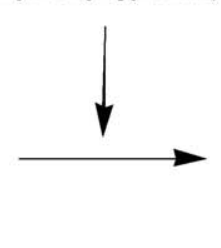
(anhydro-xylopyranose)

(2) $\stackrel{\mathrm{CHO}}{\mathrm{CHOH}}_{(\text {HAA) }}^{\mathrm{O}}$<smiles></smiles>
$\longrightarrow \underset{\mathrm{CHO}}{\mathrm{H}_{2}} \stackrel{\mathrm{C}}{\mathrm{CHO}} \rightarrow \mathrm{CO}+{\underset{\mathrm{CH}}{\mathrm{C}}}_{3}^{\mathrm{CHO}} \rightarrow \mathrm{CO}+\mathrm{CH}_{4}$

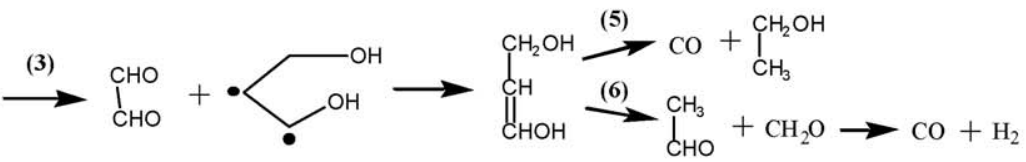

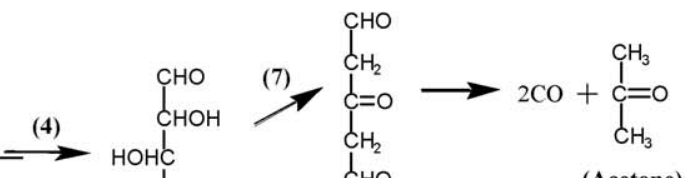
(Xylan unit) (Acetone)

(b)

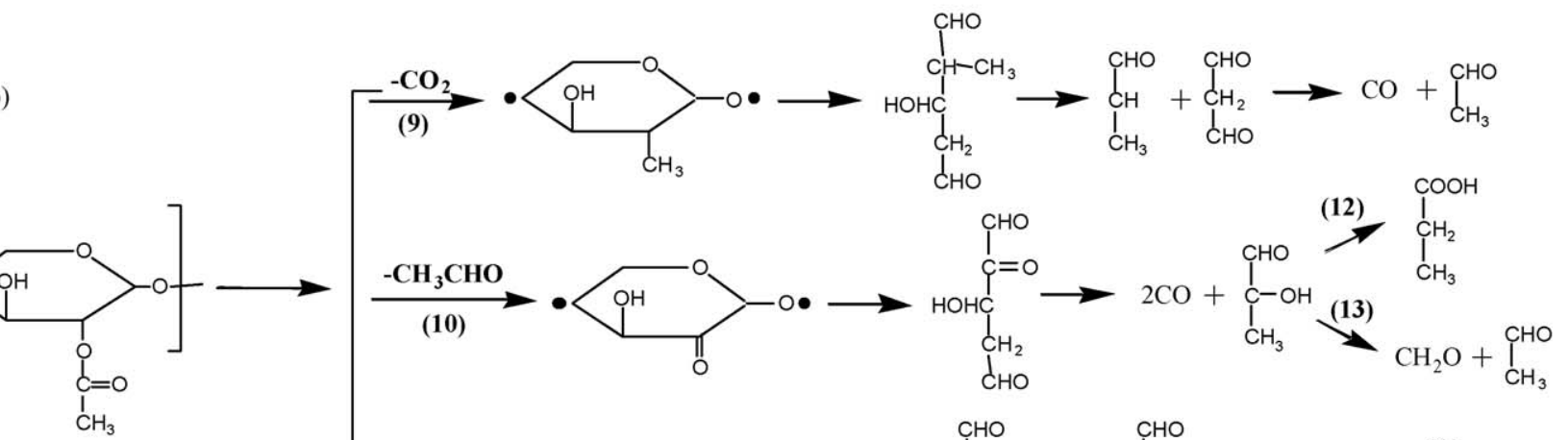
(O-acetyl Xylan unit)

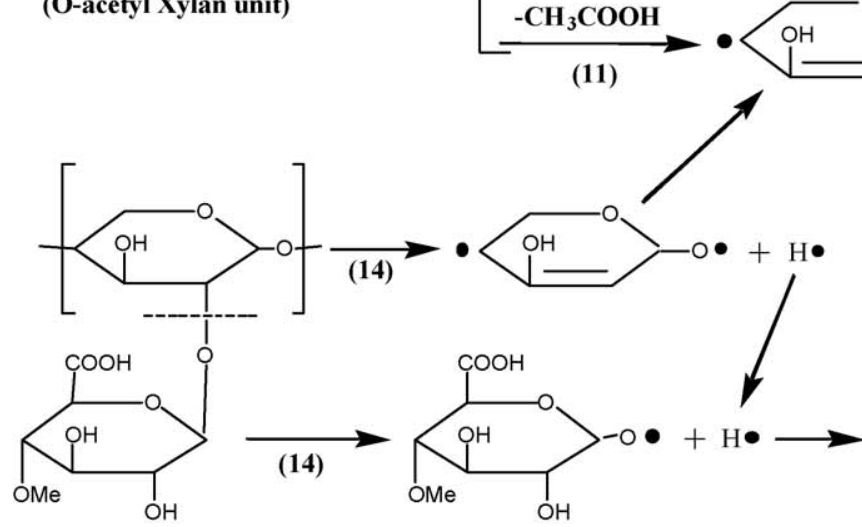
(4--O-methyl glucurono-xlyan unit)

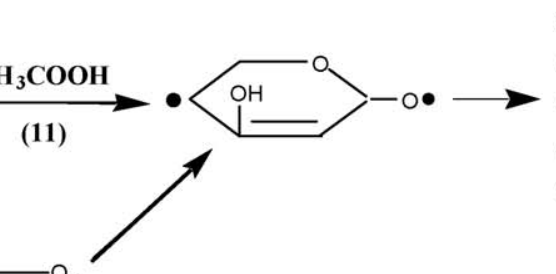<smiles>C[14C](=O)[14C](=O)C(C)(C)C</smiles>
for thermal decomposition of O-acetylxylan and 4-O-methylglucuronic acid unit.

structure of the fragment from the 4-O-methylglucuronic acid unit after the elimination of the carbonyl and O-methyl groups (secondary reaction pathway $(\mathbf{1 4}) \rightarrow(\mathbf{1 6})$ ). The pathway (11) for the formation of acetic acid is comparatively predominant over the other pathway, since the acetyl groups are in larger proportion than the 4-O-methylglucuronic acid units in the source material. It could be approved that the chemical pathway (11) is less competitive than the other two pathways (9) and (11), since the yield of acetic acid is decreased with the increased temperature. The formation mechanisms for formic acid and propionic acid are also speculated in Fig. 7b. It could be found that the formic acid is mainly produced from the elimination reaction of the carboxyl group on 4-O-methylglucuronic acid unit, accompanying the formation of $\mathrm{CO}$, hydroxylacetaldehyde and acetic acid through pathway (14) $\rightarrow(\mathbf{1 6})$. The formation of propionic acid is attributed to the chemical pathway $(\mathbf{1 0}) \rightarrow(\mathbf{1 2})$, showing a competitive mechanism with the evolution of acetic acid from the $\mathrm{O}$ acetylxylan unit through pathway (11).

Table 3 also shows the effect of temperature on the yield of methanol and acetone, presenting a slightly upward trend with the 
Table 4

The yield of the gaseous products from hemicellulose pyrolysis under different temperatures (feeding flow rate: $600 \mathrm{l} / \mathrm{h}$ ).

\begin{tabular}{lrrrrrr}
\hline Compounds & $425^{\circ} \mathrm{C}$ & $475^{\circ} \mathrm{C}$ & $510^{\circ} \mathrm{C}$ & $570^{\circ} \mathrm{C}$ & $625^{\circ} \mathrm{C}$ & $690^{\circ} \mathrm{C}$ \\
\hline $\mathrm{CO}$ (wt\%) & 5.35 & 5.23 & 6.02 & 6.93 & 9.24 & 13.33 \\
$\mathrm{CO}_{2}$ (wt\%) & 25.01 & 24.54 & 25.61 & 25.78 & 24.79 & 22.87 \\
$\mathrm{H}_{2}$ (wt\%) & 1.08 & 1.60 & 2.35 & 2.49 & 3.29 & 3.34 \\
$\mathrm{C}_{x} \mathrm{H}_{y}$ (wt\%) & 0.81 & 0.96 & 1.09 & 1.15 & 1.70 & 2.56
\end{tabular}

increased temperature for the two products. The formation of methanol is mainly attributed to the $\mathrm{O}$-methyl group on $\mathrm{C}_{4}$ position of 4-O-methylglucuronic acid unit, primarily evolved through the pathways $(\mathbf{1 4}) \rightarrow(\mathbf{1 5})$ and $(\mathbf{1 4}) \rightarrow(\mathbf{1 6})$. The yield of methanol changes slightly with the elevated temperature, due to the fact that no competitive reaction commences to consume the O-methyl groups. The formation of acetone should be complicated, as almost each unit could decompose to produce acetone (pathway (4) $\rightarrow$ (7) for xylan unit, (11) for O-acetylxylan unit and (14) $\rightarrow(\mathbf{1 5}) \rightarrow(\mathbf{7})$ for 4-O-methylglucurono-xylan unit). Since the acetic acid formed through pathway (11), together with the formation of acetone is decreased at elevated temperature, the acetone produced from the decomposition of xylan unit should be more competitive and the main contributor for the final yield of acetone.

\subsubsection{The evolution of gaseous products}

The influence of the elevated temperature on the yields of the main gaseous products $\left(\mathrm{CO}, \mathrm{CO}_{2}, \mathrm{CH}_{4}\right.$ and $\left.\mathrm{H}_{2}\right)$ is exhibited in Table 4. It is noticeable that the yields of $\mathrm{CO}$ and $\mathrm{CO}_{2}$ are much greater than $\mathrm{H}_{2}$ and $\mathrm{CH}_{4}$. The overwhelming evolution of $\mathrm{CO}_{2}$ is ascribed to the decarboxylation reaction of the large content of O-acetyl groups linked to the xylan chain normally on $C_{2}$ position $[19,20]$. More $\mathrm{CO}$ is produced at the elevated temperature while the yield of $\mathrm{CO}_{2}$ only changes slightly. It could be explained as: the formation of $\mathrm{CO}$ is highly affected by the decomposition of the ring-opened intermediate, the secondary reactions of the low molecular weight products (especially decarbonylation of the aldehyde-type compounds) [21], $\mathrm{CO}_{2}$ is presumably produced in the primary reactions. Such mechanism is revealed in the corresponding formation chemical pathways in Fig. 7a and b.

The evolution of $\mathrm{CO}_{2}$ is mainly attributed to the primary decomposition of O-acetylxylan unit through the decarboxylation reaction corresponding to the pathway $(\mathbf{9})$, and partially caused by the primary reaction of the 4-O-methylglucuronic acid through the pathway $(\mathbf{1 4}) \rightarrow(\mathbf{1 5})$ in Fig. 7a. Comparatively a large number chemical pathways could account for the formation of $\mathrm{CO}$, such as the pathway (2), (3), (4) $\rightarrow(\mathbf{7}),(\mathbf{9}),(\mathbf{1 0}),(\mathbf{1 1})$ and $(\mathbf{1 4}) \rightarrow(\mathbf{1 6})$, including the decomposition of (O-acetyl) xylan units and sidechain structure (4-O-methylglucuronic acid). Almost all of the fragments containing aldehyde-structure, such as hydroxylacetaldehyde, aldehyde and formaldehyde, can produce $\mathrm{CO}$ by the decarbonylation reactions. It should be noted that the yield of $\mathrm{CO}$ is increased at higher temperature, while the yield of $\mathrm{CO}_{2}$ and acetic acid is simultaneously decreased shown in Tables 3 and 4 . It is presumable that the pathway (10) is more competitive to consume $\mathrm{O}$-acetylxylan units to promote the formation of $\mathrm{CO}$, compared to the other two pathways $(\mathbf{9})$ and $(\mathbf{1 1})$. Thus, it is understood that the evolution of $\mathrm{CO}$ is enhanced at elevated temperature where the secondary reactions are improved.

\section{Conclusions}

The mechanisms of the hemicellulose pyrolysis and chemical pathways for the formation of its main products are extensively investigated using the TG-FTIR and Py-GC-MS. Two visible peaks in the "sharp mass loss stage" corresponding to the intensive evolution of the volatiles are characterized by the FTIR spectro- gram. It is speculated that two peaks would overlap at the high heating rate due to the enhancement of the decomposition of different xylan units.

Effects of temperature on the product yield (gas, bio-oil and char) are well discussed in the Py-GC-MS experiments. Furthermore, the formation mechanisms of bio-oil and gases are extensively investigated. The furfural and 1,4-anhydro-D-xylopyranose are mainly produced from the xylan units, while the formation of acetic acid and $\mathrm{CO}_{2}$ is attributed to the primary decomposition of O-acetylxylan unit. The xylan unit is also the main precursor for the formation of the two-carbon, three-carbon fragments and gases $\left(\mathrm{CO}, \mathrm{H}_{2}\right.$ and $\left.\mathrm{CH}_{4}\right)$. The evolution of methanol is mainly ascribed to the primary reactions of 4-O-methyglucuronic acid unit, which could be further decomposed to almost all of the products generated from the other two units. It is worth noting that the formation of acetone and $\mathrm{CO}$ could be attributed to the decomposition of the ring-opened intermediate products or secondary reactions of the fragments, obtained from all three kinds of the units in the original material.

\section{Acknowledgement}

The authors gratefully acknowledge the financial support from UK Engineering and Physical Sciences Research Council (Grant No. $\mathrm{EP} / \mathrm{G} 034281 / 1)$.

\section{References}

[1] R.P. Overend, T.A. Milne, L.K. Mudge, Fundamental of Biomass Thermochemical Conversion, Elsevier, London, 1985.

[2] G. Maschio, C. Koufopanos, A. Lucchesi, Bioresource Technology 42 (1992)219-231.

[3] T. Bridgwater, Fast Pyrolysis of Biomass, CPL, UK, 2008.

[4] S.V. Loo, J. Koppejan, Biomass Combustion and Co-firing, Earthscan, UK and USA, 2008.

[5] F. Shafizadeh, Y.Z. Lai, Journal of Organic Chemistry 37 (1972) 278-284.

[6] F. Shafizadeh, A.G.W. Bradbury, Journal of Applied Polymer Science 23 (1979) 1431-1442.

[7] R.H. Mohammed, J.B. Howard, J.P. Longwell, Journal of Industrial and Engineering Chemistry 21 (1982) 457-465.

[8] R.K. Agrawal, The Canadian Journal of Chemical Engineering 66 (1988) 403-412.

[9] G. Varhegyi, P. Szabo, W.S.L. Mok, M.J. Antal, Journal of Analytical and Applied Pyrolysis 26 (1993) 159-174.

[10] M.J. Antal, G. Varhegyi, Industrial and Engineering Chemistry Research 34 (1995) 703-717.

[11] R. Bilbao, J.F. Mastral, M.E. Aldea, J. Ceamanos, Journal of Analytical and Applied Pyrolysis 39 (1997) 53-64.

[12] J.L. Banyasz, S. Li, J.L. Lyons-Hart, K.H. Shafer, Journal of Analytical and Applied Pyrolysis 57 (2001) 223-248.

[13] T. Hosoya, H. Kawamoto, S. Saka, Journal of Analytical and Applied Pyrolysis 80 (2007) 118-125.

[14] K. Kawamoto, H. Morisaki, S. Saka, Journal of Analytical and Applied Pyrolysis (2008), doi:10.1016/j.jaap.2008.08.009.

[15] C. Di Blasi, M. Lanzetta, Journal of Analytical and Applied Pyrolysis 40-41 (1997) 287-303.

[16] M.J. Spearpoint, Predicting the ignition and burning rate of wood in the cone calorimeter using an integral model, Report Number GCR 99-975, NIST, 1999.

[17] S. Dammstrom, L. Salmen, P. Gatenholm, BioResources 4 (1) (2009) 3-14.

[18] D. Severian, Polysaccharides: Structural Diversity and Functional Versatility, 2nd ed., Marcel Dekker, New York, 2008.

[19] F. Shafizadeh, G.D. Mcginnis, C.W. Philpot, Carbohydrate Research 25 (1972) 23-33.

[20] G.R. Ponder, G.N. Richards, Carbohydrate Research 218 (1991) 143-155.

[21] T. Hosoya, H. Kawamoto, S. Saka, Journal of Analytical and Applied Pyrolysis 78 (2007) 328-336.

[22] T. Hosoya, H. Kawamoto, S. Saka, Journal of Analytical and Applied Pyrolysis 83 (2008) 64-70.

[23] T. Hosoya, H. Kawamoto, S. Saka, Journal of Analytical and Applied Pyrolysis 83 (2008) 78-87.

[24] P.A. Sandford, J. Baird, in: G.O. Aspinall (Ed.), Molecular Biology, Academic Press, New York, 1983.

[25] C. Di Blasi, C. Branca, A. Santoro, E.G. Hernandez, Combustion and Flame 124 (2001) 165-177.

[26] C. Di Blasi, Journal of Analytical and Applied Pyrolysis 47 (1998) 43-64.

[27] Q. Liu, S.R. Wang, Y. Zhen, Z.Y. Luo, K.F. Cen, Journal of Analytical and Applied Pyrolysis 82 (2008) 170-177.

[28] Y.F. Liao, Mechanism study of cellulose pyrolysis, PhD Thesis, ZheJiang University, HangZhou, China, 2003.

[29] J. Piskorz, D. Radlein, D.S. Scott, Journal of Analytical and Applied Pyrolysis 9 (1986) $121-137$ 